\section{An early warning of the risks of rocketry}

Sir - The recent study by M. N. Ross et al. on possible stratospheric pollution by rockets (Nature 390, 62-64; 1997) indicates purely local destruction of the ozone layer, with little impact on the overall geographical picture.

Probably the first engineer to alert the international community to the danger of atmospheric pollution by rockets fired into the upper atmosphere was an Englishman, C. F. Dendy Marshall, who, in a letter of 16 February 1932 to the League of Nations, called for international intervention. He was responding to an article in The Times of London of 25 August 1931 that referred to the intention of Dr Darwin O. Lyon to fire a rocket to a height of 50 miles for scientific purposes.

Marshall drew attention to the existence of hydrogen at remote altitudes which without oxygen would not burn, but he warned of the probability of "an explosive belt which the rocket would set on fire in its passage".

He went on to say: "The effect might merely be an unprecedented display of the nature of an aurora.On the other hand, the heat generated might be so great as to bring about the end of the world, so far as we are concerned. There is a risk of wiping everybody out, except those of us who were in the Tube, together with such miners as were at work...."

Marshall quoted Sir James Jeans's estimates that the proportion of hydrogen to oxygen molecules in a given volume of air at ground level was 1:21,000; at a height of 12 miles, 1:875; and at 50 miles about17:1.

Assuming that the mixture would be flammable between 25 and 30 miles, Marshall calculated that the affected volume would be 47,666 cubic miles, albeit at a very low mean pressure of 0.035 pounds per square inch. The equivalent at ground level pressure would be 113 cubic miles, "enough for a good explosion".

\section{Paul Tunbridge}

30 Avenue Krieg,

1208 Geneva,

Switzerland

Nuclear agency's research misjudged

Sir - In your News story "Nuclear agency may absorb physics institute" (Nature 389, $895 ; 1997)$, you say "the move is intended to increase CEA’s [France’s atomic energy commission's] fundamental research capacity, which is widely considered to lag behind the commission's engineering prowess".

Fundamental research is one of the important and recognized goals of CEA, and is carried out in all its divisions, and in particular in the Direction des Sciences de la Matière ('matter', not 'materials'), devoted to basic research in physics and chemistry.

Our institute employs 1,800 CEA staff, and there are 1,200 permanent employees in our laboratories from other agencies or universities, visitors and graduate students. The departments are evaluated every two years by international committees chaired by distinguished scientists.

Together with excellent advice, our laboratories have received much praise from these committees, and many DSM scientists have received national and international awards.

I must also say that I was somewhat surprised by your harsh report, given that our results are often published in Nature.

\section{Catherine Cesarsky}

(Director)

Direction des Sciences de la Matière, CEA/Saclay,

91191 Gif-sur-Yvette Cedex, France e-mail: catherine.cesarsky@CEA.fr 